\title{
The Enigma of the Stigma of Hair Loss: Why is Cancer-Treatment Related Alopecia so Traumatic for Women?
}

\author{
Coe, Kathryn ${ }^{1, *}$, Staten, Lisa ${ }^{1}$, Rosales, Cecilia ${ }^{2}$ and Swanson, Marie ${ }^{1}$ \\ ${ }^{I}$ Indiana University Richard M. Fairbanks School of Public Health, Indiana University-Purdue University, Indianapolis, \\ 714 Senate Avenue, Indianapolis, IN 46203, USA; ${ }^{2}$ Mel and Enid Zuckerman College of Public Health, University of \\ Arizona, Indiana University-Purdue University, Indianapolis, 714 Senate Avenue, Indianapolis, IN 46203, USA
}

\begin{abstract}
In both developed and developing countries, breast cancer is now one of the most commonly diagnosed reproductive cancers and a primary cause of death among women. Women treated for breast cancer are likely to receive either radiation or chemotherapy, both of which have secondary effects. Chemotherapeutic treatment produces a range of relatively immediate effects, including pain, nausea, fatigue, mouth sores, depression, problems sleeping, and temporary hair loss. Of these, women across cultures often report that hair loss is one of the more troublesome; it makes them feel unattractive and look like they are sick or dying. Further, they often feel stigmatized by others. In this paper we look at the cross-cultural patterns of responses to hair loss and examine its possible evolutionary roots. We argue that there is a deep biological basis for these emotions and that; consequently, it is important to develop specific and culturally-tailored interventions to provide support for these women.
\end{abstract}

Keywords: Cancer, alopecia, chemotherapeutic effects.

\section{INTRODUCTION}

Globally, breast cancer is the most common malignancy in both developing and developed countries [1] (Benson \& Jatoi, 2012). If these women receive treatment, such as chemotherapy, the majority will survive for at least five years. In 1985, Fritzhugh Mullen recognized that the war against cancer depended not only on the development of effective therapies but also the development of strategies for the increasing number of cancer survivors that could help minimize medical and social problems associated with the diagnosis and treatment.

In this paper, we address a social and psychological issue often faced by women in the cancer treatment phase, to which relatively little attention has been devoted. Cancer treatment, whether involving chemotherapy or radiation, produces a range of effects that have been categorized in various ways: physical [2] (Griffin, Butow, Griffin, Coates, Childs, Ellis, Dunn, \& Tattersall, 1996), social [3] (Munstedt, Manthey, Sachsse \& Vahrson, 1997), [4] psychological [5, 6] (Cash, 2001; Nerenz, Leventhal \& Love, 1982), psychosocial [2] (Griffin et al., 1996), emotional [6] (Nerenz, Leventhal \& Love, 1982), and cognitive [7] (Schagen, Muller, Boogerd, Mellenbergh, \& van Dam, 2006). More specifically, and related to treatment complexity or toxicity, symptoms can include pain, nausea, fatigue, mouth sores, depression, problems sleeping, alteration in body image and hair loss, or alopecia, and can be quite severe. Most, if not all

*Address correspondence to this author at the Indiana University Richard M. Fairbanks School of Public Health, Indiana University-Purdue University, Indianapolis, 714 Senate Avenue, Indianapolis, IN 46203, USA;

Tel: 317-278-3072; Fax: 317-274-3443; Email: coek@iupui.edu of these effects, have an impact on one's quality of life and ability to carry out activities of daily living.

As hair loss is neither a cause of physical pain nor a lifethreatening condition, it would seem to be a relatively minor effect [8] (Hilton, Hunt, Emslie, Salinas, \& Ziebland, 2008). A review of the literature, however, indicates that cancer patients, women in particular, regularly report that they feel that hair loss is a serious problem, psychologically, socially, and emotionally [5] (Cash, 2001). As Hansen [9] (2007) explains: "Hair loss has a considerable impact on the women, on their social relations and their everyday lives"(p. 24). A small percentage of women may even refuse chemotherapy because their fear of hair loss is so intense [3] (Munstedt et al., 1997).

This strong response to hair loss occurs not just in the U.S., but across cultures. Danish women, in a study conducted in three cancer rehabilitation centers [9] (Hansen, 2007 , p. 20), agreed that "it is a big deal for a girl to lose her hair." Not only did participants report they felt a loss of physical and sexual attractiveness, but they all agreed that "When you lose your hair you really look sick" (p. 21) and "Without your hair you look like someone who's going to die" (p. 22). German women (47\% of the 27 women interviewed) reported that they felt that hair loss was the most traumatic consequence of chemotherapy, more traumatic than even the loss of the breast [3] (Munstedt, Manthey, et al., 1997). Australian women $(\mathrm{n}=99)$ ranked alopecia third, just after vomiting and nausea, as the most bothersome side effect of a very long list of chemotherapy effects [10] (Coates, Abraham, et al., 1983). This response may be more severe in women diagnosed with breast cancer $[6,11]$ (Kissane et al., 1998; Love et al., 1989). 
Further, not only do these women report that they have to deal with their own personal response to hair loss, but they have to deal with the stigma responses of others. Hair loss robs them of their privacy about their illness [93] (Munstedt, Manthey, Sachsse, \& Vahrson, 1997); it "becomes a daily reminder of cancer, since the sickness of the patient suddenly becomes obvious to others" [9] (Hansen, 2007, p. 23). As Rosman explains (2004), this means that hair loss often leads them to be discredited or stigmatized. According to Batchelor (2001), "hair loss is associated with a loss of attractiveness...a state of disgrace and illness, in addition to the aging process, death, and a loss of sexuality." Continuing, he writes, that "loss of hair symbolizes the destruction of personality, diminution of self or lowering of status...Natural hair loss whether temporary or permanent is usually deplored. (p. 148)

According to Hansen (2007), "wearing of wigs and make-up can be understood as actions intended to minimize the stigmatizing effects of hair loss" (p. 23). As one woman explained, "I have worked so hard at not letting other people see I was sick -- only my husband has seen me without a wig and make-up a few times" [9] (Hansen, 2007, p. 22). The existence of "hats with hair" -- or wigs -- indicates the importance of disguising hair loss from others, as opposed to simply covering one's bald head for other reasons such as warmth or the prevention of sunburn.

\section{HAIR, BIOLOGY, AND HUMAN EVOLUTION}

Hair, in cultures located around the world, is regarded as important. According to a saying common to the Yoruba, which is an ethnic group of southwestern Nigeria, one's success or failure in life depends on the head. Indeed, members of the Yoruba ethnic group in Africa sometimes refer to humanity itself as "the species that grows hair mainly on the head" [12] (Sieber \& Herreman, 2000, p. 95).

As we see a response to hair loss across cultures, and the emotional and social responses are so immediate and intense, the evolutionary history of our species may offer us some clues as to why the loss of hair is so often and so widely reported as being traumatic. One of the identifying characteristics of mammals is the presence of hair -- all mammals and only mammals have hair. One of the first physical traits that distinguished the evolutionary path to modern humans, besides bipedal posture, may have been the loss of much of the body hair, an evolutionary event that may have occurred over a million years ago [13] (Rogers, lltis, \& Wooding, 2004). The hair that remained, including hair on the scalp, is a remnant of the insulating and protective hairiness of our ancestors [9] (Hansen, 2007). The reason why humans lost much of their body hair is unknown; however, Kushlan (1985) has proposed that the human inventions of clothes and fire meant that much of the hair on the body, the production of which can have high energy costs, was no longer necessary.

Human hair differs from that of other mammals in that the structure of the follicle is more complex [14] (Bernard, 2005). Consequently, human head hair continues to grow and can get quite long, while animal hair stops growing when it reaches a certain length and is eventually shed [15]
(Thierry, 2005). This growth, Thierry (2005) argues "is the critical character giving humans control of their head hair. It provides an abundant and renewed matter allowing for the shaping of hair style and obtaining elaborated forms" (p. 5). The genetic changes that allowed for the continuous growth of hair, he continues, "happened just prior to the emergence of Homo sapiens." This speculation is echoed by Jolly (2005) who proposes that "Coiffure and coiffure-demanding genes could be at least as old as Homo sapiens."

For humans, temporary or permanent hair loss, or the excessive shedding of normal human hairs from normal telogen follicles, was probably a fairly rare event in our ancestral past [16] (Kligman, 1961). Temporary loss could have been brought about by a variety of stressors including illness and exposure to certain of the parasitic pests with whom we coevolved.

Grooming is often one of the most time-consuming pastimes for many species, including birds, fish, and mammals [17] (Stewart, 1998). In mammals, that are often characterized by the development and maintenance of complex social relationships, grooming can be an important part of building, and one might add, maintaining, social relationships [18] (Sugiwara, 1984). It seems plausible that early in our evolutionary history, humans also used hair grooming to strengthen social ties. Grooming behaviors in humans have been greatly expanded and now include cutting, adorning, removing, or decorating one's own hair or the hair of others.

Hair not only is linked to socialization, but, being obvious - as hair grows out of our head -- it is public. Unless covered, hair is always on view [19] (Weitz, 2004) and visible at a social distance. Further, head hair is located in close proximity to the human face, an area that Donald Symons called "the most information-dense part of the human body" (quoted in Ridley 2003, p. 296). Our tendency to pay close attention to the faces of other humans would probably coincide with paying attention to their hair. Studies of facial recognition indicate that an important part of our memory of an individual may involve encoding that person's hair [20] (Wright \& Sladden, 2003); even infants are able to recognize faces and gender using information about sex-typical hair length (Leinbach \& Fagot, 1993 [21]).

Humans have long been able to "read" hair, whether or not it is culturally modified. This ability to interpret potentially important social cues based on one's hair would have been critically important as humans became increasingly social [22] (see Gates, 1957). Scalp hair, in its natural state, regularly communicates such things as ancestry, age, health, and sexual attractiveness.

Hair as a marker of ancestry: The concentration of hair follicles, in humans, is highly influenced by genes and varies by race or ethnicity (Wesley, N. O. \& Maibach, H. I.,2003 [23]. Biologically, hair often serves as a marker of ancestry, or human genotype. Caldwell (2003), in a study of black women in Brazil, referred to hair texture as a marker of ancestry. Dione-Rosado (2004) explains, "Hair texture is evaluated consciously and unconsciously to authenticate the African genotype. In the African diaspora, "hair is even more important than skin color, language, or religion because it serves as a critical marker of race and group identity" (p. 61). 
Hair as a marker of age: The greying of the hair, which is biological indicator of aging and increasing maturity [9] (Hansen, 2007), has always elicited a social response. The ethnographic record devotes a great deal of attention to descriptions of differential respect accorded to the grey-haired elderly. For example, in regard to the Cherokee, Fogelson (1963) writes "Wisdom was symbolized by grey hair, the immediately perceptible evidence of successful adjustment to omnipresent dangers lurking in the natural and supernatural environment" (p. 728). As an example of the power accorded these older, grey-haired women, a child's taskmistress among the Aymara of South America is an older woman (e.g., mother, sister, mother-in-law) who has unquestioned authority [24] (Mitchell, 1998, p. 55). Further, the older woman's authority was not just over other women. Among the Inuit, "most men defer to the opinion and wish of a 'grandmother' as they will to one else," even though those women could be outspoken critics of males [25] (Guemple, 1995, p. 22).

Hair as a marker of general health: Hair has been seen across cultures as a biological indicator of general health. Symons (1979) observed that because "luxuriant hair" (e.g., thick, shiny, manageable = the so-called "healthy hair") may be universally attractive during our evolutionary history, it has been "reliably associated with health and vigor" (p. 187) and with a woman's beauty and power or influence [26] (Weitz, 2001). Hair also is an indicator of illness; among many groups, including the Tonga [Polynesia] [27] (Clark, 1975), Hopi [southwestern United States] [28] (Beaglehole \& Beaglehole, 1927) and Azande [North Central Africa] [29] (Abbott, 1950), the condition of one's hair was used to diagnose illness. Jolly (2005) writes that messy or untended hair can suggest that the "wearer is desperate, or insane, and furthermore, has no friends." As hair is a fast growing tissue, and is likely to make demands on the body, it is not surprising that dry and listless hair, and hair loss, served as an indicator of severe or chronic protein-calorie malnutrition. Further, hair loss can be a sign that one has an infection [30] (Araujo, et al, 2002). Hair loss can also indicate that a person is physically and emotionally vulnerable as a result of having recently experienced intense serious emotional trauma [27] (Clark, 1975). While hair loss - baldness, temporary or permanent - probably did occur in our ancestral history, it rarely occurred in females and when it did, it often communicated the presence of a serious health problem.

Hair and sexual selection: Hair, perhaps related to its biological communication of age and health, is often described as a woman's glory (1 Corinthians, 11:15). Hair, particularly when culturally adorned, as is discussed in the next section, is seen as so sexually attractive that some religions mandate the covering of a woman's hair at puberty or after marriage because, according to Koppelman (1996), covering the hair "signifies the renunciation of personal vanity and discourages sexual attraction from males other than her own" (p. 88). Across cultures there is a clear association made between a woman's hair and her sexual attractiveness [31] (Delaney, 1994). Bartman (2001) explained that in ancient Rome, "hair was a major determinant of a woman's physical attractiveness" (p. 1). Hair, it seems to be clear, has some sexual significance and cultural practices, as we discuss next, augment or discourage this attraction.

\section{CULTURE AND HAIR}

In humans, hair is malleable [32] (Synnott, 1993), and unlike much of body decoration such as tattooing or scarification, can be altered without physical pain. Hair can be arranged in many different ways and, even when cut, grows back, continually replenishing itself [33] (Koppelman, 1996). The cultural (or socially learned) modification of the hair - e.g., using particular hair styles - is an ancient practice [34] (Synnott, 1987), the antiquity of which provides additional support for its evolutionary importance. By the Upper Paleolithic (between 30,000 and 10,000 years ago), there is evidence of hair arrangements and perhaps use of hair nets in the carved figures often referred to as Venus figurines [35] (Berman, 1999). There also may be evidence of hair ornamentation, using mud, clay, feathers, and bone, in the human figures depicted in prehistoric cave paintings [36] (Sherrow, 2006). Today, hair according to Delaney (1994), "is an object of intense elaboration in many societies; seemingly the most superficial part of the human body, its meanings are nevertheless deeply rooted in culture" (p. 159).

The modification of the hair, as mentioned before is an ancient practice. Further, it is a very widespread practice. "Styling of hair," Mercer (1990) explains, was a universal cultural practice and the arrangement of the hair on one's head "is never a straightforward biological fact for it will always be worked upon by human hands" (pp. 248-249). In the ethnographic record of societies that have a kinshipbased social structure, a structure that closely resembles that of our distant ancestors, there is clear evidence of cutting, decorating, and arranging hair; a wide range of arrangements, styles, and decorations were used for a large number of purposes. Leach (1958), in his paper, Magical Hair, argued that virtually every known society has culture-specific hair styles and has attached cultural significance to those hair styles [32, 37-40] (1958, see also Frazer, 1935, Leach, 1958, Hallpike 1969; Obeyesekere, 1984; Synnott, 1993). Hallpike (1969), when writing about cutting hair ( although his same claims can readily be applied to other forms of hair arrangement and styling), argues that the specific form of hair cutting, or styling, was a form of communication, communicating specific social messages and implying conformity to social rules.

Hair styles, across cultures and at perhaps the most basic level, exaggerate or, in some cases hide, information that already is, to some extent, being communicated biologically: gender, ancestry, and age. Hair styles, Choi (2006) explained, have probably long been used to exaggerate or emphasize differences between males and females, particularly males and younger females. Perhaps Hemingway said it best: "a girl just isn't a girl without her hair" or, as it was explained by Bartman (2001), "[a] that at the most basic level a female's hair signaled her female sex" (p. 2).

Further, the style of one's hair also communicated one's ancestry through use of tribal or clan specific hair styles [41, 42] (Coe, 1993; 2003). According to White and White (1995), in African cultures, the grooming and styling of hair were important rituals and elaborate hair designs - involving cutting, shaping, wrapping and braiding often with beads and shells - reflected tribal or ethnic group affiliation. 
To some extent the particular hair style was also associated with age or age grade. Among the Lepchas of the Himalayas, as just one example, a child's hair was kept short; after puberty, when she was betrothed, a woman's hair was never to be cut [43] (Gorer, 1938). Although wigs and coloring of the hair, using such things as clay, were used in tribal groups, they were often used in ceremonies to depict an ancestral being or some mythical creature (see description in Spencer \& Gillen, 1927, p. 150) or as part of a mourning ritual. Signs of aging were not hidden. According to Davidson (1949), native Australian women in Queensland applied gypsum or pipeclay to their hair, not to hide their age, but to form a mourning cap and communicate their status as widows. It is only in larger scale societies, with more complex social organization and loss of respect for the elderly, that wigs or coloring may come to be used to hide the grey hair of age or even the ravages of illness (see Nelson, 2011). Barrett (1952) reported that among the Pomo of California, women who had experienced the death of kin cropped their hair very short either by cutting it with an obsidian knife or burning it off with a fire brand. The forward half of the head then was covered with many small spots of white paint. The Aranda of Australia had elaborate funerary practices, which included female kin cutting off their hair (Glowczewski, 1983 [4]). Iban women in Borneo, young and old, all cut their hair when mourning [44] (Sandin \& Sather, 1980).

The removal of hair also could signal disgrace. To provide an example, a Danish woman who consorted with a German soldier during World War II, had her hair shaved after the liberation. This woman reported: "It didn't ruin my life, but it has followed me and marked me for life" (cited in Warring, 1995, p. 42). In several parts of the world, including Tikopia [Solomon Islands] [45] (Firth, 1959), thieves would have their hair cut off in order to shame, stigmatize and punish them [46, 47] (Benoliel, 1996, p. vii; Biddiscombe, 2001).

While this discussion could continue at great length, the point has been made that hair has been an important device for communicating status and has consistently been associated with such things as loss of attractiveness, illness, aging, death, and even disgrace [48] (Batchelor, 2001). It is perhaps for this reason, that hair loss related to breast cancer may be particularly traumatic as it can involve the loss and/or modification of the hair and breast, both of which are associated with attractiveness and aging. In addition, hair is often seen as powerful and it is often claimed that removing the hair of others gives one power. Native people in Southern Australia (Glowczewski, 1983) used the hair cut from the dead to weave a net that was worn by living kin as it was said to protect them from harm. Forcibly removing someone's hair, perhaps the hair of a competitor, enemy, or a perceived criminal, as in the case of the Danish woman discussed above, is seen as an act of ritual punishment.

Although male status can also be identified by hair style, the response of males to hair loss, while few studies have been completed on this topic, may be less severe than that of females [5] (Cash, 2001) and the response may be due to concerns about aging not about hair loss per se [49] (DeMuro-Mercon, Rhodes, Girman, \& Vatten,' 2000). This may be related to the fact that it is not unusual for males to experience some baldness during maturity; Hippocrates noted that while men became bald, neither eunuchs nor children did [50] (Whiting, 1998). Cash (2001) proposes that evolutionary function of male baldness might have been to signal that the male was less aggressive, had higher social status, and wisdom, and thus could serve as a teacher to younger male members of the group [51] (see also Muscarella \& Cunningham, 1996).

\section{DISCUSSION AND APPLICATION}

Our Argument: To summarize our argument, over a million years ago our human ancestors began to lose much of their body hair, with several exceptions, including hair located on or near the face. The hair that remained was used to identify crucial information about the age, gender, health, and ancestry of individuals. The first recorded cultural modification of the hair occurred perhaps 30,000 years ago; over time the modification of hair (e.g., decoration, arrangement) was done in all known cultures and used to communicate a large range of things, including one's tribal affiliation and ancestry, marital status, punishment or social deviance, etc. Hair loss associated with disease, albeit perhaps rare, may have occurred early in human evolution, as hair loss is associated with some of the parasitic pests with whom we coevolved [30] (Araujo, et al., 2002). The importance of using the hair to communicate, and the stigmatization aimed at those who are experiencing hair loss, appear to be ancient products of our biological evolution and cultural history. Due to these deep evolutionary roots, the strong psychological response of the female cancer patient to her loss of hair and the possibly equally strong judgmental response of the viewer - disease avoidance -- are not likely to easily disappear. Stigmatization, and the emotions associated with it (e.g., fear, disgust, revulsion) may have evolved to help us avoid being exposed to diseases that could kill us.

The Problem: Even though women feel strongly about hair loss, and are stigmatized by the reactions of others, hair loss may not be an issue regularly or adequately addressed by their physicians or others, perhaps because it seems to be such a minor issue [52] (Sleven, et al., 1990). The growing numbers of women who are diagnosed with cancer each year, however, indicate that preparing women for the hair loss that will occur as a result of chemotherapy is important. Further, preparing the women's significant others, for their own response to the hair loss and helping them avoid the appearance of being non-supportive and judgmental, are also important.

Potential Solutions, Emotional Preparation: When preparing women prior to the initiation of treatment, however, they need more than just to be told that they will lose their hair and that when their hair grows back it may be of another color and may have a different texture, and that wigs and scarves are available through various organizations [48, 53] (Batchelor, 2001; Wagner \& Bye, 1979). Women need to be emotionally and socially prepared. A physician, who experienced hair loss due to chemotherapy, reported that even though she was intellectually well prepared for the experience, she was not emotionally prepared: "the physical reality of the hair falling out posed emotional and practical problems which I had not anticipated. For 2 weeks I was in tears every morning, plucking the clumps of hair from all over the 
bedclothes" [48] (Batchelor, 2001). While women facing chemotherapy related hair loss probably would not want to be taught about the biological roots of the response, they do need to be prepared for the intensity of their own response, and the response of others to their hair loss [2, 53] (see Wagner \& Bye, 1979 and review in Griffin, et al., 1996).

Potential Solutions, An Evolutionary Approach to Education: There are certain facts we can draw from our evolutionary past and descriptive data from small-scale societies, and from evidence-based promotion programs, that may shed light on emotions and how humans learn and consequently what we may need to do in the area of health education to help these women. These programs should recognize the biological underpinnings of the trauma and focus on important social and cultural influences on human behavior.

Social Aspects: To begin, evolutionarily speaking, we humans are a highly social species; we evolved in small groups of kin. Social support is particularly crucial when we are in vulnerable positions. If we are to help a cancer survivor build and sustain a strong social support system, the careful and detailed preparation of kin and others, such as close friends, who will support her through her cancer journey, or any journey involving hair loss, is critical. While kin provided this support for much of human history [54] (see Flinn, Quinlan, Coe, \& Ward, 2004), these systems largely have broken down in westernized societies. What the evidence in public health seems to make clear is that relationships established upon trust are more likely to be influential. Trust is established through such things as recognition of a common background and culture [55] (Van Lange, Rusbult, Drigotas, Arriaga, \& Witcher, 1997). Research supports that strong social ties, in which trust has been established, are conduits to the successful acquisition of knowledge [55-57] (Ghosal et al., 1994; Hansen, 1999, Van Lange, et al., 1997).

Cultural Aspects: Further, humans have complex culture. As anthropologists and members of tribal societies have long recognized [58, 59] (see Wolff, 2000; Giroux, 1992), culture plays an important role in teaching and learning. The importance of culture has also been recognized in public health; as Airhihenbuwa noted (1994), culture clearly is theoretically important in teaching and health promotion. The importance of incorporating culture into health promotion and education is increasingly being recognized in education and health promotion fields [59] (see Giroux, 1992). To quote Kreuter, Lukwage, Bucholtz, Clar, and Sander-Thompson (2003), "It is a truism of health education that programs and interventions will be more effective when they are culturally appropriate for the populations they serve" (p. 133). This could involve incorporating such things as the arts, including storytelling, music and theatre into our health promotion designs [41, 60-64] (Adams, 2002; Burton, Horowitz, \& Abeles, 2000; Catterall, 1998, 2005; Coe, 1993; Coe \& Keller, 1996).

An example of storytelling used in promoting health was described by Geanellos (1996), who explained,

As a teaching-learning technique storytelling engages learners; organizes information; allows exploration of shared lived experience without the demands, responsibilities and consequences of practice; facilitates remembering; and en- hances discussion, problem posing and problem solving...(p. 28).

The use of storytelling may involve telling the story of the life and responses of a mythical woman who had experienced hair loss and been traumatized by it, but by drawing on such things as her support system, and using them effectively, came through the event with minimal trauma. If stories are to be effective in influencing attitudes and behaviors, Hartling, et al., (2010), write, "the ability of the reader to relate to the stories and identify with the characters, has been identified as a key factor" (p. 8). The emotional power of using such stories is described in this same paper: "one reviewer said the stories brought tears to her eyes as she recalled her own similar experiences" (p. 8).

By adding images to our teaching modalities, particularly those that involve reading, we have incorporated the visual arts. Research supports that incorporating visual images into text can support comprehension, as students often move back and forth between the text and illustrations using external visual images to support their comprehension of what they are reading [65] (Hibbing \& Rankin-Erickson, 2003). Although little work has been done on the role that the visual arts might play in education, Marshall, Gold-Smith and Forrest (2004) did find in their study that visual art was a "an innovative and adaptive methodology to promote breast health" (p. 233).

If we combine visual art with music, as is often done in advertising campaigns $[42,66]$ (see discussion in Bagozzi \& Silk, 1983; Coe, 2003), we are basically using theatre to promote health. As tribal leaders and health educators have long recognized, and public health now recognizes, theatre can be used effectively to educate, teaching via observation and to promote retention of knowledge [67-69] Brown \& Gillespie, 1997; Coe, Aiken, \& Palmer, 2006; Ségun \& Rancourt, 1996; Stuttaford, Bryanston et al., 2006). Theatre could be used to teach women strategies that they could draw upon - e.g., methods for tempering their response - that help minimize the critical response of others and the stigma she feels.

One also might consider using humor to promote health and teach. Humor is widely used across cultures to defuse tense situations and decrease anxiety and discomfort and, as research studies have supported, can be effective in promoting learning $[70,71]$ (Ziv, 1988, see also Kaplan \& Pascoe, 1977). The use of humor has also been found to help create an environment in which a woman is more likely to openly discuss her concerns [72] (Christie \& Moore, 2005).

An additional point here is that helping a woman adjust to her hair loss and her feelings that she is no longer attractive, may involve changing her values and the values of those around her. According to Wagner and Bye (1979: 368), rather than focusing on hair loss, women should be encouraged to focus on such things as "spiritual values, a sense of inner worth, and strengthened family relationships." Unfortunately, while this may seem logical, if we add the task of changing a woman's values to our health promotion programs, we should consider that value systems are formed over time, beginning early in a woman's long developmental period and are a product of the social relationships she has 
maintained and the skills she has acquired $[42,73,74]$ (Coe, 2003; Kohlberg, 2008, Rogoff, 2003). While we can tell a woman that her appearance is not important and she should not be ashamed of her response, and this message may remind her of similar messages she has heard during her life, to try to profoundly modify her values would be very difficult as it would involve unraveling and changing years of developmental learning and challenging important social relationships. As values are social, or shared, changing a woman's values would also involve changing the values of her peers and family members, as they form the environment that now either supports or fails to provide support for her values and her needs. As Wagner and Bye (1979) pointed out, our own body image is partially, or perhaps profoundly, based on the cues and responses of those around us. Helping individuals adjust to those cues and responses may be an important part of any health promotion program, but particularly those for women who have experienced temporary hair loss.

A final point we wish to make here is that an important part of modifying the response to hair loss may lie in modifying the fear response. We have suggested here that fear of the sick, and behaviors aimed at avoiding those who are sick, may be an adaptive response, one selected in ancestral generations. The adaptive nature of this response is supported by the fact that it occurs when hair loss occurs in children, their parents often consider keeping their children out of school in order to avoid the potential ridicule that might occur in response to the hair loss [75] (Katz et al., 1977). In ancestral generations, those who avoided people who looked sick, avoided being exposed to disease, and thus were likely to live longer and be able to better care for their offspring. This suggests that this particular fear response may be hardwired, not just based on information stored in one's memory as may occur in other situations [76] (Foa \& Kozak, 1986). We live, however, in an environment that deviates greatly from that of our distant ancestors. As Eberly, Harkness and Engdahl (1991) have pointed out, the difference between a response that is seen as adaptive or maladaptive today may be a function of how much our current environment differs from that of those distant ancestors. Today, we have no reason to fear and avoid a woman who is undergoing cancer treatments involving radiation or chemotherapy.

The fear response, as many have argued, is the most primitive form of psychological stress; it has been referred to as a "prerational response, meaning that it relies on a number of evolutionary inherited responses to threatening stimuli and is effective in situations in which a rapid response, such as running away or avoidance, is adequate [77] (see Christopher, 2004). Humans, however, differ from many other species, with which we share the fear response, in that we have large brains and a capacity for learning and rationality that may be a tool to overcoming such responses. The goal of an intervention, as Christopher (2004) argues, "should be on assisting the patient to develop the metacognitive reconfiguration of schema needed to turn anxiety into meaning" ( $p$. 92). This would involve, he suggests, drawing heavily on culture, including the use of images, music, and storytelling not just to modify the trauma felt by the cancer patient who has lost her hair but to prevent the negative response of those who are around her.

\section{CONCLUSION}

In conclusion, within the larger context of cancer diagnosis and treatment, the loss of hair may be seen to be a relatively trivial matter. However, documentation of women's reports of their own response to hair loss, and the stigmatized response of others, indicates that it is a much more significant issue than might be expected. An examination of head hair throughout human history provides a framework to understand this seeming contradiction. For women in particular, the hair on the head is a symbol of her sexual attractiveness, physical health and cultural identify, all of which are important aspects of a woman's self-identity. In the case of a woman undergoing treatment for breast cancer, two important symbols of her womanhood, attractiveness and health are affected. A key role of health promotion is to assist individuals cope with their illnesses. By only superficially addressing hair loss, an opportunity is lost to more deeply affect a woman's emotional health. Utilizing an evolutionary framework, focused on how humans learn and have taught over time, can inform health promotion activities by incorporating art, music, and storytelling. This approach holds promise for enhancing the quality of life of female cancer survivors.

\section{CONFLICT OF INTEREST}

The author(s) confirm that this article content has no conflicts of interest.

\section{ACKNOWLEDGEMENT}

This project was supported by Grant Numbers U01 CA86122 and U01 CA111496 from the National Institutes of Health/National Cancer Center. Its contents are solely the responsibility of the authors and do not necessarily represent the official views of the NIH/NCI.

\section{REFERENCES}

[1] Benson JR, Jatoi I. The global breast cancer burden. Future Oncol 2012; 8(6): 697-702.

[2] Griffin A, Butow P, Coates A, et al. On the receiving end V: Patient perceptions of the side effects of cancer chemotherapy in 1993. Ann Oncol 1996; 7: 189-95.

[3] Munstedt KMN, Sachsse S, Vahrson H. Changes in self-concept and body image during alopecia induced chemotherapy. Supp Care Cancer 1997; 5: 139-43.

[4] Glowczewski B. Death, women and "value production" the circulation of hair strings amounth the Walpiri of the Central Australian Desert. Ethn 1983; 22(3): 225-39.

[5] Cash WF. The psychology of hair loss and its implications for patient care. Clin Dermatol 2001; 19(2): 161-6.

[6] Love R, Leventhal H, Easterling M, Nerenz D. Side effects and emotional distress during cancer chemotherapy. Cancer 1989; 63: 604-12.

[7] Schagen SB, Muller MJ, Boogerd W, Mellenbergh GJ. van Dam FS. Change in cognitive function after chemotherapy: A prospective longitudinal study in breast cancer patients. J Natl Cancer Inst 2006; 98(23): 1742-5.

[8] Hilton SHK, Emslie C, Salinas M, Zieland S. Have men been overlooked? A comparison of young men and women's experience of chemotherapy-induced alopecia. Psychooncology 2008; 17(6): 577-83.

[9] Hansen HP. Hair loss induced by chemtherapy: An anthropologial study of women, cancer, and rehabilitation. Anthropol Med 2007; 14(1):15-26. 
[10] Coates AAS, Kaye S, Sowerbutts T, Frewin C, Fox R, Tattersall M. On the receiving end-patients perception of the side effects of cancer chemotherapy. Eur J Can Clin Oncol 1986; 19: 203-8.

[11] Kissane D, Clarke D, Ikin J, et al. Psychological morbidity and quality of life in Australian women with early stage breast cancer: A cross-sectional survey. Med J Aust 1998; 169(4): 192-6.

[12] Sieber R, Herreman F, Museum for African A. Hair in African Art and Culture. München: Prestel 2000.

[13] Rogers A, Iltis D, Wooding S. Genetic variation at the MC1R loc and the time since loss of human body hair. Curr Anthropol 2004; 45(1): 105-9.

[14] Bernard BA. The biology of hair follicle. J Soc Biol 2005; 199(4): 343-8.

[15] Thierry B. Hair grows to be cut. Evol anthropol evolutionary anthropology: Issues, News Rev 2005; 14(1): 5-. English.

[16] Kligman A. Psychological dynamics of human hair loss. AMA Arch Dermatol 1961; 83: 175-98.

[17] Stewart D. The Importance of Getting Clean. Int Wildl 1998; 28(2): 12-21. English.

[18] Sugiwara K. Spatial proximity and bodily contact among the Central Kalahari San. African Sudy Monographs, Supplementary Issue 1984.

[19] Weitz R. Rapunzel's daughters: What women's hair tells us about women's lives. New York Farrar, Straus and Giroux 2004.

[20] Wright D, Sladden B. An own gender bias and the importance of hair in face recognition Acta Psychol 2003; 114(1): 101-14.

[21] Leinbach MDF, B. I. Categorical habituation to male and female faces: Sender schematic processing in infancy. Infant Behav Dev 1993; 16: 317-32.

[22] Gates RR. Forms of hair in South African races. Man 1957; 57: 813.

[23] Wesley NOM, H. I. Racial (Ethnic) differences in skin properties. Am J Clin Dermatol 2003; 4(12): 843-60.

[24] Mitchell W. Women's hierarchies of age and suffering in an Andean community In: Brown JD-PaJ, Ed. Women Among Women: Anthropological perspectives on female age hierarchies. Urbana: University of Illinois Press 1998. pp. 52-64.

[25] Guemple L. Gender in Inuit society. In: Ackerman LKaL, Ed. Women and Power in Native North America. Norman University of Oklahoma Press 1995. pp. 17-27.

[26] Weitz R. Women and their hair: Seeking power through resistance and accommodation. Gender Soc 2001;15(5): 667-86.

[27] Clark WF. Population, agriculture and urbanizion in the Kindgom of Tonga. Ann Arbor University of Microfilms International; 1975.

[28] Beaglehole E, Beaglehole P. Notes on Hopi economic life. New Haven; London: Pub. for the Section of Anthropology, Department of the Social Sciences, Yale University, by the Yale University Press; H. Milford, Oxford University Press 1937.

[29] Abbott PH. A Survey of Signs on Nutritional III-Health among the Zande of the Southern Sudan. Khartoum: Agricultural Publications Committee, Ministry of Agriculture, Sudan Government. 1950; pp. 157-68.

[30] Araujo A, Ferreira L, Guidon N, et al. Ten Thousand Years of Lice Infection In: Ember PPaM, Ed. Encyclopedia of Prehistoric, 7 South America, . Norwell, MA: Kluwer Academic Publishers 2002. pp. 272-9.

[31] Delaney C. Untangling the meanings of hair in Turkish society. Anthropol Quart 1994; 67(4): 159-72.

[32] Synnot D. The body social. London Routledge 1993.

[33] Koppelman C. The politics of hair. Frontiers: J Women's Stud 1996; 17(2): 87-8.

[34] Synnott A. Shame and glory: A sociology of hair. Br J Sociol 1987; 38(3): 381-413.

[35] Berman JC. Bad hair days in the Paleolitihic: Modern (re)construction of the cave man. Am Anthropol, (New Series). 1999; 101(2): 288-304.

[36] Sherrow V. The encyclopedia of hair. . Westport, CT: Greenwood Publishing 2006.

[37] Frazer J. The Golden bough. New York: Macmillan 1935.

[38] Leach ER. Magical hair. J R Anthropol Inst 1958; 88(2):147-67.

[39] Hallpike CR. Social Hair. Man 1969; 4(2): 256-64. English.

[40] Obeyesekere G. Medusa's hair. Chicago: University of Chicago Press 1984.

[41] Coe K. Art: The repliciable unit. J Soc Evol Syst 1993; 15(2): $217-$ 34.
[42] Coe K. The Ancestress Hypothesis. Newark: Rutgers University Press 2003.

[43] Gorer G. Himalyan village: an account of the Lepchas of Sikkim London Michael Joseph, Ltc 1938.

[44] Sandin BS. Iban Adat and Augury Penang: Penerbit Universiti Sanis Mayaysia for School of Comparative Sciences 1980.

[45] Firth R. Social change in Tlkopia New York The Macmillan Company 1959.

[46] Benoliel JQ. Suffering In: Farrell BR, Ed. Duarte 1996.

[47] Biddiscombe P. Dangerous liaisons: The anti-fraternization movement in the U.S. Occupation Zoes and Germany and Austria, 1945-1948. J Sociol Hist 2001; 34(3): 611-47.

[48] Batchelor D. Hair and cancer chemotherapy: Consquences and nursing care-A literature study. Eur J Cancer Care 2001;10:147-63.

[49] DeMuro-Mercon CRT. Girman C, Vattern L. Male pattern hair loss in Norwegian men. Dermatology 2000; 200(3): 219-22.

[50] Whiting D. Male pattern hair loss: Current Understanding. . Int J Dermatol 1998; 37(8): 561-6.

[51] Muscarella F, Cunningham MR. The evolutionary significance and social perception of male pattern baldness and facial hair. Ethol Sociobiol 1996; 17: 99-117.

[52] Sleven M, Stubbs L, Plant $\mathrm{H}$, et al. Attitudes toward chemoptherapy. Comparing views of patients with cancer with thos of doctors, nurses, and the general public. Br Med J 1990; 300: 1458-60.

[53] Wagner L, Bye M. Body image and patients experiencing alopecia as a result of cancer chemotherapy. Cancer Nurs 1979; 2(5): 365-9.

[54] Flinn M, Quinlan R, Coe K, Ward C. Evolution of the human family: Cooperative males, long social childhoods, smart mothers, and extended kin networks. In: Shackelford CASaTK, Ed. Family relationships: A evolutionary perspective. New York Oxford University Press 2004. pp. 16-38.

[55] Van LP, Rusbult C, Drigotas S, Arriaga X, Witcher B. Willingness to sacricife in close relationship. J Pers Soc Psychol 1997; 72(6): 1371-95.

[56] Ghoshal S, Korine G, Szulanski G. Interunit communication in multinational corporations. Management Science 1993; 40: 96-110.

[57] Hansen M. The search transfer problem: The role of weak ties in sharing knowledge across organization subunits. Acad Manag J 1999; 44: 82-111.

[58] Wolff N. The use of human images in Yoruba medicines. . Ethnol 2000; 39(3): 205-24.

[59] Giroux HA. Border Crossings. New York Routledge 1992.

[60] Adams J. Art in social movements. Sociol Forun 2002; 17(1): 21 56.

[61] Burton J, Horowitz R, Abeles H. Learning in and through the arts The question of transfer. Stud Art Educ 2000; 3: 228-57.

[62] Catterall J. Does experience in the arts boost academic achievement? A response to Einsner. Art Educ Stud 1998; 51(4): 68.

[63] Coe K, Keller C. Health protective behaviors of young African American women: should be using a kindship model to teach health behaviors. . J Hum Ecol 1996; 4: 57-66.

[64] Catterall J. Conversation and Silence: Transfer of Learning Through the Arts: eScholarship, University of California; 2005. Available from: http://www.escholarship.org/uc/item/6fk8t8xp

[65] Hibbing ANR-E, JL. A Picture Is Worth a Thousand Words. The Reading Teacher. 2003; 56(8): 758-70.

[66] Bagozzi R, Silk A. Recall, recognition, and the measurement of memory for print advertising. Market Sci 1983; 2: 95-134.

[67] Brown K, Gillespie D. "We become brave doing brace acts" Teaching moral courage through the theather of the oppressed. Literat Med 1997; 16(1): 108-20.

[68] Coe K, Aiken N, Palmer CT. Once upon a time: ancestors and the evolutionary significance of stories. Anthropol Forum 2006; 16(1): 21-40.

[69] Stuttaford M, Bryanston CI, Lewando HG, Connor M, Thorogood M, Tollman S. Use of applied theatre in health research dissemination and data validation: A pilot study from South Africa. Health 2006; 10(1): 31-45.

[70] Ziv A. Teaching and learning with humor: experiment and replication. J Exp Educ 1988; 57(1): 5-15.

[71] Kaplan RPG. Humorous lectures and humorous examples: Some effects on comprehension and retention. J Educ Psychol 1977; 69(1): 61-5. 
[72] Christie WMC. The impact of human on patients with cancer. Clin J Oncol Nurs 2005; 9(2): 211-8.

[73] Kohlberg L. The development of children's orientations toward a moral order. Hum Dev 2008; 51: 8-20.

[74] Rogoff B. The Cultural nature of human development. Oxford: Oxford University Press 2003.

[75] Katz ER, Kellerman J, Rigler D, Williams KO, Siegel SE. School intervention with pediatric cancer patients. J Pediatr Psychol 1977; 2(2): $72-6$
[76] Foa EKM. Emotional processing of fear: Exposure to corrective information. Psychol Bull 1986; 99(1): 20-35.

[77] Christopher M. A broader view of trauma: A psychosocialevolutionary view of the role of the traumatic stress response in the emergence of pathology and/or growth. Clin Psychol Rev 2004; 24: 75-98.

Received: May 22, 2013

Revised: September 10, 2013

Accepted: September 11, 2013

(C) Kathryn et al.; Licensee Bentham Open.

This is an open access article licensed under the terms of the Creative Commons Attribution Non-Commercial License (http://creativecommons.org/licenses/by-nc/3.0/) which permits unrestricted, non-commercial use, distribution and reproduction in any medium, provided the work is properly cited. 